\title{
A methodology for ranking and hazard identification of xenobiotic organic compounds in urban stormwater
}

Baun, Anders; Eriksson, Eva; Ledin, Anna; Mikkelsen, Peter Steen

Published in:

Science of the Total Environment

Link to article, DOI:

10.1016/j.scitotenv.2006.05.017

Publication date:

2006

Document Version

Publisher's PDF, also known as Version of record

Link back to DTU Orbit

Citation (APA):

Baun, A., Eriksson, E., Ledin, A., \& Mikkelsen, P. S. (2006). A methodology for ranking and hazard identification of xenobiotic organic compounds in urban stormwater. Science of the Total Environment, 370, 29-38. https://doi.org/10.1016/j.scitotenv.2006.05.017

\section{General rights}

Copyright and moral rights for the publications made accessible in the public portal are retained by the authors and/or other copyright owners and it is a condition of accessing publications that users recognise and abide by the legal requirements associated with these rights.

- Users may download and print one copy of any publication from the public portal for the purpose of private study or research.

- You may not further distribute the material or use it for any profit-making activity or commercial gain

- You may freely distribute the URL identifying the publication in the public portal 


\title{
A methodology for ranking and hazard identification of xenobiotic organic compounds in urban stormwater
}

\author{
A. Baun *, E. Eriksson, A. Ledin, P.S. Mikkelsen \\ Institute of Environment and Resources, Bygningstorvet, Building 115, Technical University of Denmark, DK-2800 Kgs. Lyngby, Denmark
}

Received 7 March 2006; received in revised form 19 May 2006; accepted 24 May 2006

Available online 30 June 2006

\begin{abstract}
The paper presents a novel methodology (RICH, Ranking and Identification of Chemical Hazards) for ranking and identification of xenobiotic organic compounds of environmental concern in stormwater discharged to surface water. The RICH method is illustrated as a funnel fitted with different filters that sort out problematic and hazardous compounds based on inherent physico-chemical and biological properties. The outcomes of the RICH procedure are separate lists for both water phase and solid phase associated compounds. These lists comprise: a justified list of compounds which can be disregarded in hazard/risk assessments, a justified list of stormwater priority pollutants which must be included in hazard/risk assessments, and a list of compounds which may be present in discharged stormwater, but cannot be evaluated due to lack of data. The procedure was applied to 233 xenobiotic organic chemicals (XOCs) of relevance for stormwater. Of these 233 compounds, 121 compounds were found to be priority pollutants with regard to solids phases (i.e. suspended solids, soil, or sediments) when stormwater is discharged to surface water and 56 compounds were found to be priority pollutants with regard to the water phase. For $11 \%$ of the potential stormwater priority pollutants the screening procedure could not be carried out due to lack of data on basic physico-chemical properties and/or data on bioaccumulation, resistance to biodegradation, and ecotoxicity. The tiered approach applied in the RICH procedure and the focus on the phases relevant for monitoring or risk assessment in the aquatic environment refines the list of "compounds of concern" when compared to the outcome of existing classification schemes. In this paper the RICH procedure is focused on effects in the aquatic environment exemplified with xenobiotic organic compounds (XOCs) found in urban stormwater, but it may be transferred to other environmental compartments and problems. Thus, the RICH procedure can be used as a stand-alone tool for selection of potential priority pollutants or it can be integrated in larger priority setting frameworks.
\end{abstract}

(C) 2006 Elsevier B.V. All rights reserved.

Keywords: Risk assessment; Organic chemicals; Hazard; Toxicity; Biodegradation; Bioaccumulation

\section{Introduction}

The need for assessing the environmental hazards of xenobiotic organic compounds (XOCs) in stormwater is increasing and in the European Union this concern has been accentuated by the introduction of the Water Framework Directive (WFD) (European Commission, 2000).

\footnotetext{
* Corresponding author. Tel.: +45 452515 67; fax: +45 45162850.

E-mail address:anb@er.dtu.dk (A. Baun).
}

With the principles of good ecological and chemical status of surface water laid down in the WFD, regulators need to perform hazard assessments of chemicals found in surface water bodies in the EU. Environmental hazard assessments are often synonymous with comparing concentrations of a few selected priority pollutants with water quality standards or predicted no-effect concentrations (PNEC) (e.g. European Commission, 2003). Discharges of urban stormwater have been identified as one of the major sources of XOCs in surface water (e.g. Makepeace 
et al., 1995; Bickford et al., 1999; Eriksson et al., 2005). However, the regulator is often faced with the question: "Have we included all the worst chemicals in the assessments?" The seemingly ever increasing number of XOCs found in environmental samples calls for a focused strategy for conducting hazard and risk assessments. In most cases, it is neither possible nor relevant to carry out full hazard assessments for all chemicals identified in a sample, but on the other hand it may be difficult for the regulator to make decision on which chemicals to include and which to exclude in a hazard assessment.

Though the terminology in risk assessment procedures differs significantly, the initial step in all risk assessment procedures is the problem/hazard identification (Christensen et al., 2003). Numerous ranking procedures and screening tools for hazard identification of chemical substances are described in the literature (e.g, Swanson et al., 1997; Swanson and Socha, 1997; Hansen et al., 1999; Snyder et al., 2000). These procedures focus on priority setting for chemical regulation purposes, but are rarely directly applicable for end-users such public water managers. The procedures are typically produced by specialists for specialists.

In this paper a screening procedure for the identifying and ranking of hazardous compounds in urban stormwater discharges is presented. The RICH procedure (Ranking and Identification of Chemical Hazards) may be visualized as a funnel fitted with filters designed to reduce the number of XOCs for which hazards assessments are needed. The use of a "filter"-approach in the present paper is inspired by work presented by Müller-Herold et al. (2005), who developed a screening approach for preselection of new organic chemicals with an emphasis on global chemical threat scenarios. In contrast to the procedure presented by Müller-Herold et al. (2005), the $\mathrm{RICH}$ procedure is focused on the effects of XOCs in the aquatic environment, with the present paper concentrating on the chemicals found in urban stormwater. The procedure is aimed at end-users at the regulatory and administrative level and could be used as a stand-alone tool or as an integrated part of the Chemical Hazard Identification and Assessment Tool (CHIAT) developed recently for selection of the most critical pollutants in relation to handling strategies of stormwater and wastewater. This tool has been described in detail by Eriksson et al. (2005) and Ledin et al. (2005).

\section{Methodology}

The methodology consists of a decision tree in which problematic and hazardous compounds are identified and passed on to a hazard assessment step which involves an identification of receptors, exposure pathways, and effects assessments, leading to estimations of risk quotients (e.g., ratio between predicted environmental concentrations (PEC) and predicted no-effect concentrations (PNEC)).

The decision tree is shown in Fig. 1. To visualize the sorting of chemicals we describe the decision tree as a funnel fitted with several different filters. The filters are equivalent to each stage in the decision tree and as shown in Fig. 1, the filters separate the chemicals into four groups:

1. White compounds: Not priority pollutants as judged from hazard potential in aquatic ecosystems. This means that these compounds will be excluded from the hazard assessment.

2. Grey compounds: These compounds may or may not be priority pollutants depending on the outcome of the subsequent filtrations.

3. Black compounds: Priority pollutants. These compounds are classified as hazardous and thus directly passed on to a receptor and exposure identification, which may lead to an estimation of PEC/PNEC ratios.

4. Compounds for which data are lacking and hazard identification cannot be performed

In all filters the input data are the inherent properties of each chemical, e.g. the Henry's law constant $\left(K_{\mathrm{H}}\right)$, solubility in octanol $\left(K_{\text {ow }}\right)$, or biodegradability. As far as possible the input data are the results of determinations made using standardized test methods (e.g. ISO, OECD, ASTM).

It is emphasized that concentrations of compounds are not considered at this stage of the assessment procedure, but are included at a later stage of the CHIAT procedure for those compounds, which have been identified as priority pollutants (Eriksson et al., 2005). Furthermore, the focus in the present context is on urban stormwater being discharged directly into surface water. This means that, for example, the infiltration of stormwater and potential threats to groundwater quality are not covered by the method presented here.

\subsection{Funnels}

An initial objective is to divide the compounds into those, which mainly are water borne and those, which have a high sorption potential such that they are preferentially transported by suspended solids and/or incorporated in sediments. Therefore, two funnels are operated at the same time: one for "water phase compounds" and one for "solid phase compounds". Some compounds may of course be regarded as being both associated with the water and solid phases as a result of their inherent physico- 


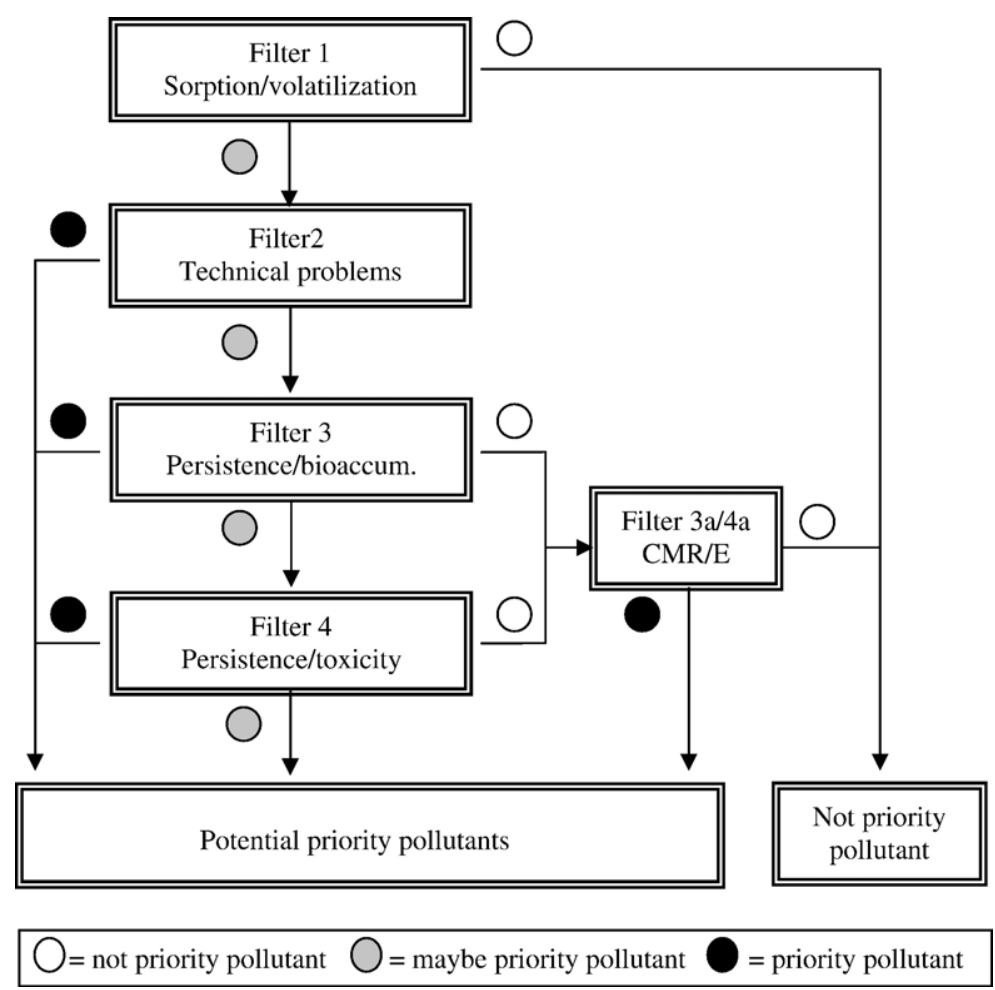

Fig. 1. Decision tree for identifying potential priority pollutants in discharged stormwater.

chemical properties, whereas others may be considered hazardous in only one of the compartments.

\subsection{Selection of parameters and construction of filters}

The parameters selected as being particularly important in determining the fate and effects of xenobiotic organic compounds in stormwater were: volatility from aqueous solution, affinity to suspended solids, resistance to biodegradation, potential for bioaccumulation, aquatic toxicity, and long-term effects (carcinogenicity, mutagenicity, potential for reproductive damage, and endocrine disruption - $(\mathrm{CMR} / \mathrm{E}))$. All of these parameters were selected in accordance with the EU Technical Guidance Document for risk assessment of chemicals (European Commission, 2003). Furthermore, the parameter "known technical problems" was included to catch compounds that may give rise to technical (precipitation and corrosion) and/or aesthetic (odour, foaming, coloring) problems when the stormwater is discharged to surface water.

The filters for evaluation of inherent environmentally relevant physico-chemical properties (i.e. affinity to suspended solids, volatility from aqueous solution, resistance to biodegradation, bioaccumulation, and toxicity) are constructed as shown in Figs. 2 and 3. The values assigned to each of the parameters result in classifications as "low", "medium", and "high". These designations can be controversial, but to circumvent endless discussions on the "right values", we chose to let cut-off values for "low" and "high" be based on international agreements (e.g. OSPARand POP-conventions) and a literature review covering cut-off values proposed by expert groups (e.g. ISO and OECD), stake-holders (e.g. industry and NGOs) and regulations in European countries, EU, USA, and Canada. Thus, "low" and "high" cut-off values are set as worst-case
Filter 1a: Water phase compounds

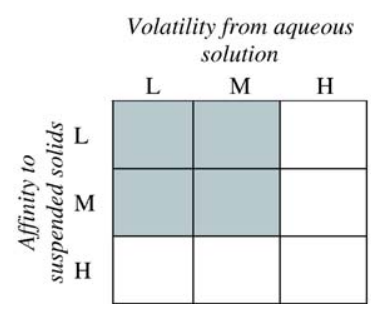

Filter 1b: Solid phase compounds

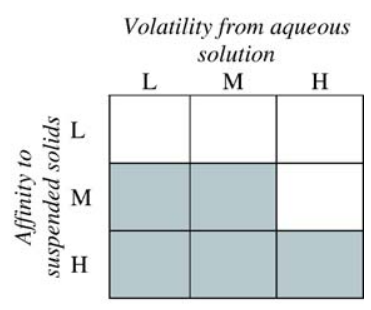

Fig. 2. Filters $1 \mathrm{a}$ and $1 \mathrm{~b}$ for testing affinity to suspended solids behaviour versus volatility from aqueous solution. Cut-off values for $L$ (low), $M$ (medium), $H$ (high) are listed in Table 1 . White fields: not priority pollutants as judged from hazard potential in aquatic ecosystems. Grey fields: may or may not be priority pollutants depending on the outcome of the following filtrations. Black fields: potential priority pollutants. 
Filter 3:

Resistance to biodegradation vs. bioaccumulation

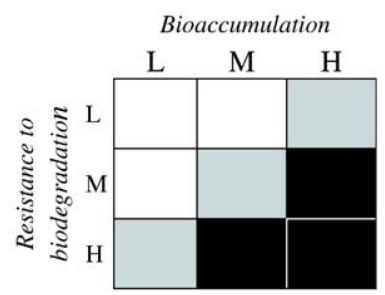

Filter 4:

Resistance to biodegradation vs. toxicity

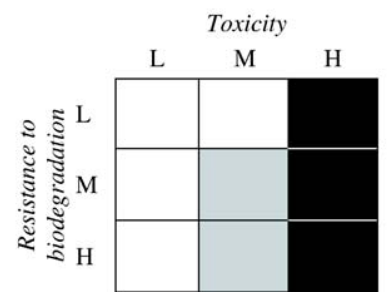

Fig. 3. Filter 3 for testing resistance to biodegradation versus bioaccumulation. Filter 4 for testing resistance to biodegradation versus toxicity. Cut-off values for $L$ (low), $M$ (medium), $H$ (high) are listed in Table 1 . White fields: not priority pollutants as judged from hazard potential in aquatic ecosystems. Grey fields: may or may not be priority pollutants depending on the outcome of the following filtrations. Black fields: potential priority pollutants.

values. The "medium" values do therefore cover the grey zone, where discussions are on-going and no final international agreements have been reached so far. The cut-off values for designated "low", "medium", or "high" parameter values are shown in Table 1 .

Depending on the combination of parameter values, the cells in Figs. 2 and 3 will be black, grey or white. The filters for the evaluation of problematic properties and $\mathrm{CMR} / \mathrm{E}$ are easier to assign, as they are designed as "on/ off filters".

\subsection{Affinity to suspended solids and volatility from aqueous solution (Filter 1)}

The first filter (see Fig. 1) is designed to separate compounds into "water phase compounds" and "solid phase compounds". This is done by comparing the sorp- tion potential of the chemical to the potential for volatilization from aqueous solution. In this case the underlying assumption is that the water is transported in open systems facilitating good contact between the air and water phases, i.e. an equilibrium between water and air is quickly established. The volatility from aqueous solution of a compound is judged from the Henry's law constant with cut-off values as shown in Table 1 . The evaluation of the affinity to suspended solids of the compound is based on the $K_{\text {oc}}$-value (cf. Table 1 ) representing the minimum affinity of the compound to suspended solids. The filters for identifying "water phase compounds" and "solid phase compounds" are presented in Fig. 2. The Filter 1a and Filter $1 b$ in Fig. 2 are operated in parallel. Thus, all compounds designated as "grey" after Filter $1 \mathrm{a}$ or Filter $1 \mathrm{~b}$ are passed on to Filter 2 (see Fig. 1). The use of two filters in the first stage of the procedure enables identification of

Table 1

Cut-off values used for volatility from aqueous solution, affinity to suspended solids, degradability, bioaccumulation, and toxicity

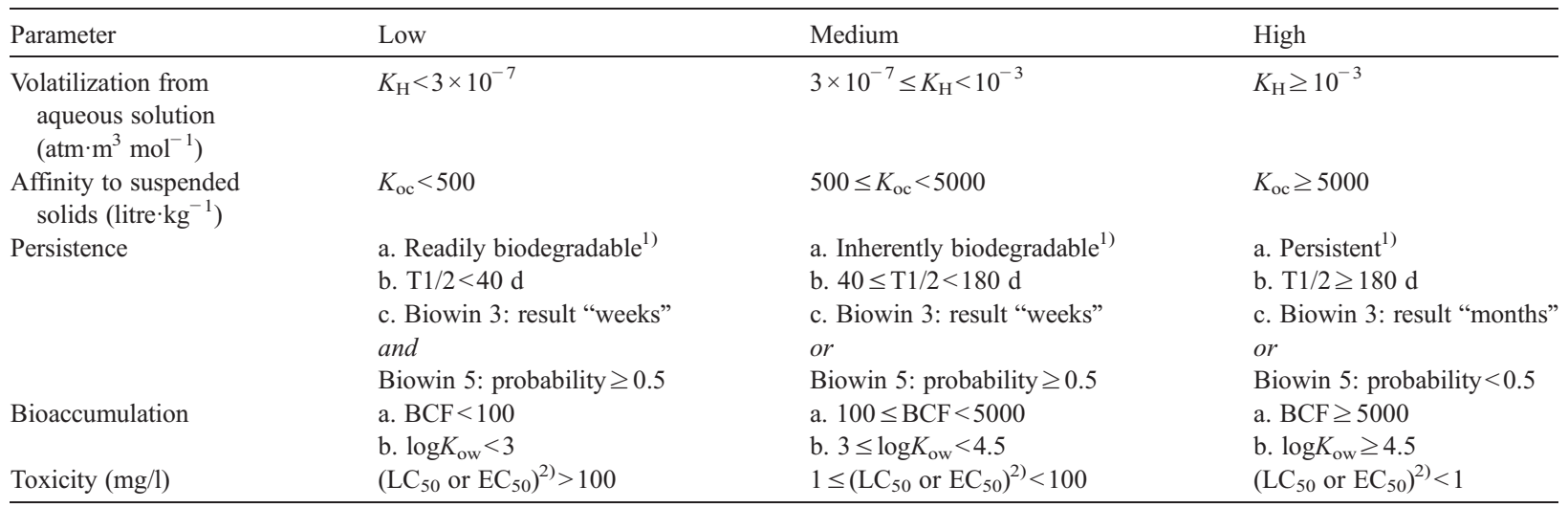

$K_{\mathrm{H}}$ : Henry's law constant — partition coefficient between air and water; $K_{\mathrm{oc}}$ : partition coefficient between organic carbon and water; $K_{\mathrm{ow}}$ : partition coefficient between $n$-octanol and water; T1/2: 1st order degradation half-life; Biowin: biodegradability models no. 3 and 5 included in EpiSuite 3.12 (US-EPA, 2005); BCF: bioconcentration factor; $\mathrm{LC}_{50}$ : lethal concentration ( $50 \%$ mortality); $\mathrm{EC}_{50}$ : effect concentration (50\% effect).

${ }^{1)}$ Classification according to standard OECD/ISO tests for ready and inherent biodegradability.

${ }^{2)}$ Data from all three tests in the base set of standardized freshwater toxicity tests (fish, crustacean, algae). 
compounds relevant to the water phase and compounds relevant to solid phases. Using these filters, very volatile compounds (i.e. $K_{\mathrm{H}}>10^{-3} \mathrm{~atm} \cdot \mathrm{m}^{3} \cdot \mathrm{mol}^{-1}$ ) will be identified as "white compounds" in relation to discharging stormwater to surface water. In case of high potential for volatilization from aqueous solution and high sorption potential the compound will however be identified as a "grey compound" which are passed on to the following filters. This is due to the fact that the affinity to suspended solids may be stronger/faster than the potential for volatilization and this type of compounds may therefore be problematic solid phase contaminants.

It should be noted that no compound will be designated as "black" as a result of the first filtration, as Filters 1a and $1 \mathrm{~b}$ merely deal with the phase distribution of the compounds and do not cover any hazards.

Compounds with acid/base-properties constitute a special case as their affinity to suspended solids and volatilization behaviour depend on the speciation of the compound. Therefore, the Henry's law constants and sorption constants for organic acids with $\mathrm{p} K_{\mathrm{a}}$-values $<9$ or organic bases with $\mathrm{p} K_{\mathrm{b}}$-values $>4$ are recalculated taking speciation at environmentally relevant $\mathrm{pH}$-values into account.

\subsection{Technical problems (Filter 2)}

The potential technical problems are evaluated based on literature data on odor, color, potential for forming foam, and/or precipitates and corrosion. The filter is a simple yes/no decision, where "yes" results in a designation as a "black compound" and "no" leads to a classification as a "grey compound" (see Fig. 1). The "black compounds" from Filter 2 are therefore directly included in the problem and hazard assessment. These compounds may at a later stage in the risk assessment be left out of consideration due to relatively low concentrations and thereby low risk of technical problems. It should however be emphasized that these compounds must be transferred back to Filter 3, as no evaluation of the environmental hazards of the compounds has been made. The outcome of Filter 2 cannot be a "white compound" (cf. Fig. 1) as the absence of potential for technical problem does not automatically mean that the compound is non-hazardous to the environment.

\subsection{Resistance to biodegradation versus bioaccumulation (Filter 3)}

In Filter 3 the environmental hazardousness of the compounds is evaluated by comparing the compound's resistance to biodegradation in water with the potential for bioaccumulation. The construction of the filter is shown in Fig. 3 and the cut-off values used are listed in Table 1.

The evaluation of resistance to biodegradation is based on results from standardized OECD/ISO tests for ready and inherent biodegradability. If these data are not available, but degradation half-lives have been reported, the latter are used according to the criteria listed in Table 1. If no half-lives are available, estimation of the biodegradability is made using the BioWin software included in the EpiSuite program (US-EPA, 2005) following the recommendations made by Boethling et al. (2004) as outlined in Table 1.

The potential for bioaccumulation is assessed from bioconcentration factors (BCF-values) reported in literature. If these are not available the octanol-water partition coefficient is used as shown in Table 1.

The construction of the filter is based on the assumption that neither high resistance to biodegradation nor high potential for bioaccumulation as single parameters are enough to deem a compound as hazardous. Compounds with these characteristics may however very well be hazardous and therefore they are designated as "grey compounds" and are passed on to Filter 4. Compounds with other combinations of high resistance to biodegradation and/or high potential for bioaccumulation are "black compounds" due to the expected environmental hazards connected with these compounds. On the other hand, compounds with a combination of low resistance to biodegradation (i.e. readily biodegradable) and low potential for bioaccumulation are designated as "white compounds" in Filter 3 and are not passed on to Filter 4. These compounds are however screened for potential for causing long-term adverse effects (cf. Fig. 1).

\subsection{Resistance to biodegradation versus toxicity (Filter 4)}

The "grey compounds" identified in Filter 3 are evaluated in Filter 4 with respect to their resistance to biodegradation and their short-term toxicity assessed from results of standardized tests with a base set of freshwater organisms (including fish, crustacean, and algae). Filter 4 is shown in Fig. 3 and the cut-off values are listed in Table 1 . The color designation takes into account that only "grey compounds" from Filter 3 are passed on to Filter 4, i.e. compounds with the following combinations of resistance to biodegradation (= persistence, $\mathrm{P}$ ) and potential for bioaccumulation (B): 1. High $\mathrm{P} /$ low $\mathrm{B}, 2$. Medium $\mathrm{P} /$ medium $\mathrm{B}$, and 3. Low $\mathrm{P} /$ high $\mathrm{B}$. Therefore, all compounds with low toxicity are categorized as "white compounds" due to the fact that persistent compounds 
(high P) reaching Filter 4 will have low potential for bioaccumulation and compounds with high bioaccumulation potential (high B) will be readily biodegradable (low P), cf. Fig. 2. Compounds with medium toxicity are categorized as "white" or "grey" depending on their P/B profile from Filter 3, but very toxic compounds reaching Filter 4 are always evaluated as "black compounds".

In the present version of the screening tool we have included only four filters, and therefore the "grey compounds" from Filter 4 are not passed on to another filter, but are regarded as "black compounds", i.e. potential stormwater priority pollutants. However, if further criteria need to be included as a fifth filter, the "grey compounds" from Filter 4 are identified by the present procedure could be processed accordingly. As was the case for the "white compounds" from Filter 3, the "white compounds" from Filter 4 are also screened for their potential for causing long-term adverse effects.

\subsection{Long-term effects (Filters $3 a$ and $4 a$ )}

As shown in Fig. 1, Filters 3a and 4a are added to the decision tree, in order to catch compounds, which are identified as "white" compounds by Filters 3 and 4, but which may potentially give rise to long-term toxic effects. Compounds with known potential for causing cancer, mutation or reproductive damages (so-called CMR compounds) and/or endocrine disrupting compounds (socalled EDC compounds) are directly identified as "black compounds" The potential for causing these effects are evaluated from the danger labeling of the individual compounds (R-sentences: R40, R45-46, R49, R60-64) and literature surveys.

\subsection{Outcome from filtration}

The outcome from the hazard and problem identification procedure is three separate classifications:

1. A justified list of compounds which can be excluded from hazard/risk assessments ("white list").

2. A justified list of potential priority pollutants which must be included in hazard/risk assessments ("black list").

3. A list of compounds which may be present in discharged stormwater, but cannot be evaluated due to lack of data.

These three lists form the basis for decision making in relation to risk assessment of XOCs in urban stormwater. Furthermore, the procedure identifies compounds for which data on inherent properties are lacking and no evaluation can be performed.

\subsection{Initial test of the procedure}

To test the functionality of the RICH procedure a test set consisting of 11 organic compounds (di(2-ethylhexyl) phthalate (DEHP); tributyltin (TBT); triphenyl phosphate (TPP); benzo(a)anthracene (BaA); naphthalene; 2(2,4-dichlorophenoxy)propionic acid (dichlorprop); tertbutyl methyl ether (MTBE); pentachlorophenol (PCP), phenol, C-12 linear alkylbenzene sulphonate (LAS), and acetic acid) was used. The compounds represent a range of well-known environmental priority pollutants with different fate and effect patterns. Acetic acid was included as an expected non-problematic "control compound".

\subsection{Potential priority pollutants}

Following the initial testing procedure, a large-scale filtration of stormwater relevant XOCs was carried out. For this purpose a database consisting of inherent physico-chemical data etc. was constructed, in order to make an automated version of the "funnels and filters" screening procedure. Compounds of relevance were selected according to the CHIAT procedure described by Eriksson et al. (2005) and CAS numbers were used as chemical identifiers in the handbooks and databases used to collect data.

\section{Results and discussion}

\subsection{Results from the test set}

The results of applying the procedure to the $11 \mathrm{com}-$ pounds in the test set are shown in Fig. 4. As would be expected, very different profiles were obtained in relation to water and solid phase contaminants. The compounds DEHP, TBT and BaA are identified as "black compounds" in relation to solid phase contamination, but are "white compounds" in relation to water phase. This means that these three compounds are priority pollutants, and that potential problems related to these compounds can be anticipated in solid phases (e.g. soil, sediments, and suspended solids). The compounds TPP, naphthalene and PCP are examples of compounds, which are priority pollutants in both the water and solid phases, whereas dichlorprop, phenol, and acetic acid are examples of compounds, which could be omitted from further risk assessments. Furthermore, PCP is an example of an organic acid for which the $\mathrm{p} K_{\mathrm{a}}$-evaluation described 


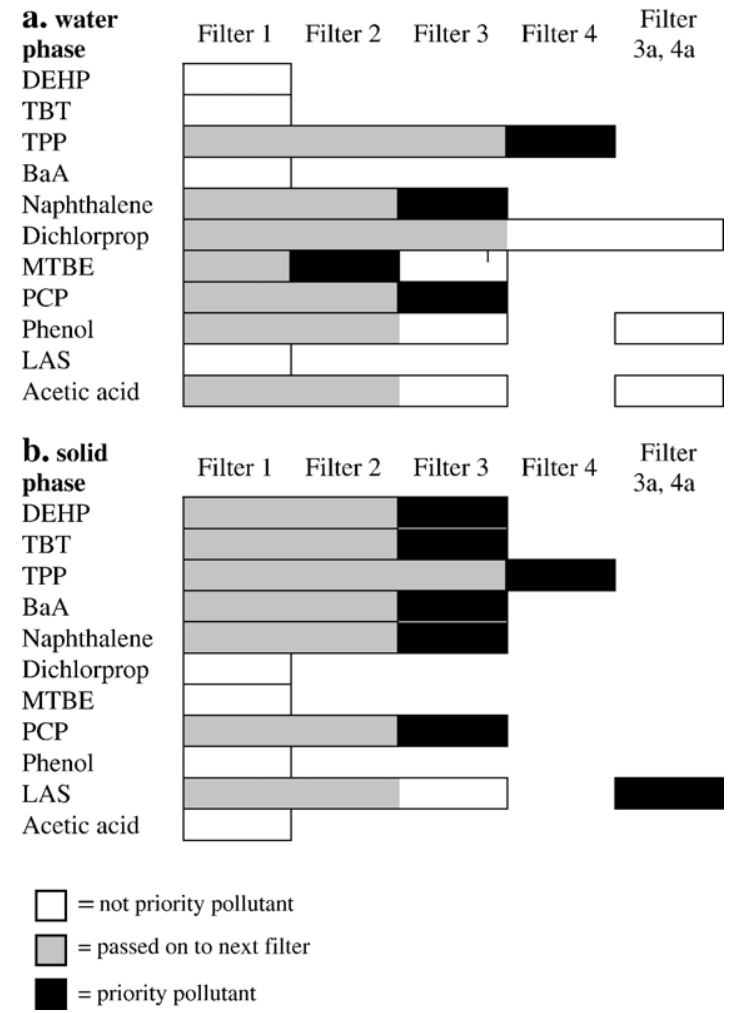

Fig. 4. Results of screening of 11 organic chemicals using the "funnels and filters" procedure. a. Evaluated in relation to water phase, b. evaluated in relation to solid phase. ${ }^{1} \mathrm{MTBE}$ result of second screening of MTBE. DEHP: di(2-ethylhexyl)phthalate; TBT: tributyltin; TPP: triphenyl phosphate (TPP); BaA: bezo(a)anthracene; MTBE: tertbutyl methyl ether; PCP: pentachlorophenol (PCP), LAS: linear alkylbenzene sulphonate.

previously is necessary to identify the compound as a water phase priority pollutant.

MTBE is a very water-soluble compound and is therefore not a priority pollutant in relation to solid phases. In the water phase, a technical problem may occur due to a strong odor and MTBE is therefore identified as a "black compound" in Filter 2 (Fig. 4). MTBE should therefore go through the problem and hazard assessment steps of the traditional chemical risk assessment scheme. In this case the risk assessment should focus on the technical problems of MTBE. If MTBE is found to be non-problematic at this stage (e.g. the environmental concentration is far below the odor threshold), the compound must be tested in Filter 3, as the environmental hazards of MTBE have not been addressed at Filters 1 and 2. When this is done, MTBE turns out to be a "white" compound (high persistence, low bioaccumulation) and no hazard assessment is needed.

The compound LAS is strongly sorbing $\left(K_{\mathrm{oc}}\right.$ calculated from experimentally derived sorption coefficients) and is therefore a "white compound" in relation to the water phase (see Fig. 4). Due to the fact that LAS is a readily biodegradable compound under aerobic conditions and has a low potential for bioaccumulation it is also identified as "white" in relation to solid phase (see Fig. 4). However, LAS is known to be persistent under anaerobic conditions and may for this reason be identified as a priority pollutant in e.g. sludge from municipal wastewater treatment plants. The special fate pattern of LAS leads to our recommendation of including data on anaerobic degradability in Filters 3 and 4. If this is done, LAS is identified as a "black compound" in Filter 3, and should be added to the list of potential stormwater priority pollutants in relation to solid phases. LAS is actually identified as a "black compound" in terms of its long-term toxicity reported in the literature (i.e. LAS is "black" in the CMR/ E filter in Fig. 4).

\subsection{Screening for potential stormwater pollutants}

Fig. 5 shows the results of applying the RICH procedure to a database containing information on 233 potential stormwater priority pollutants. For $62 \%$ of these compounds no further hazard assessment needs to be done for the water phase due to the fact that the compounds are not associated with the water phase (104 compounds) or do not have a PBT-profile that match the criteria of "black" compounds in Filters 3 and 4 (40 compounds). The corresponding result for potential solid phase priority pollutants is that $36 \%$ ( 85 compounds) are evaluated to be "white compounds". This is mainly due to the expected chemical distribution pattern, i.e. 76 of the 85 "white" compounds were identified as not relevant for solid phase after Filter 1. This example illustrates, that the regulator can clearly identify why certain chemicals are considered as "white" compounds following the RICH-procedure. Thus, the regulator can critically review whether or not these compounds really should be regarded as "safe" in the actual case under consideration.

A total of 56 compounds were found to be priority pollutants with regard to the water phase and 7 compounds were in the grey zone indicating the possibility of becoming priority pollutants. For these 63 compounds additional hazard assessments need to be done. Thus, the use of the RICH procedure reduced the number of compounds relevant for hazard assessment in the water phase by a factor of four. Of the 233 compounds in the stormwater database, 121 compounds were found to be priority pollutants with regard to solids phases (i.e. suspended solids, soil, or sediments) when stormwater is discharged to surface water. Of these 121 compounds, 33 were also found to be priority pollutants in the water phase. 
Water phase

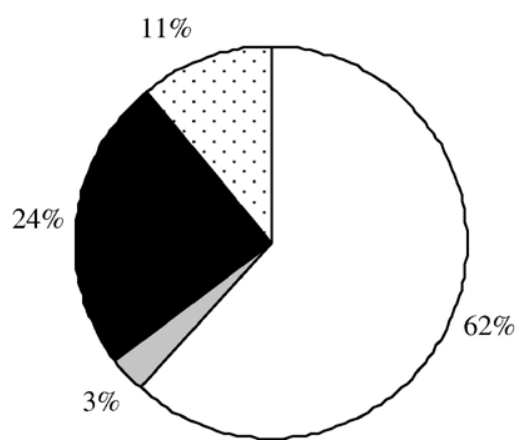

Solid phase

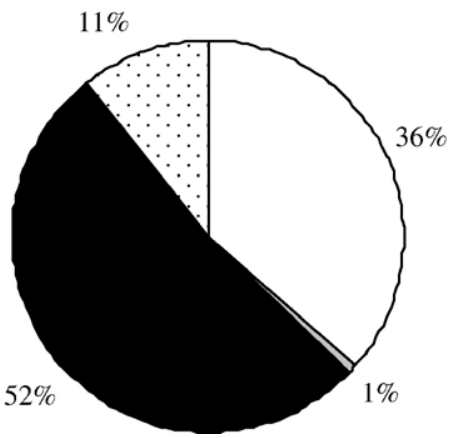

Fig. 5. Result of screening of 233 potential stormwater priority pollutants. White: not stormwater priority pollutant, Grey: maybe stormwater priority pollutant; Black: stormwater priority pollutant; dotted: no classification possible due to lack of data.

Fig. 6 shows the number of "black" compounds distributed between various groups of organic chemicals. For the solid phase compounds it is observed that a majority of the compounds fit into four well-known groups of problematic chemicals, i.e. polyaromatic hydrocarbons (PAH, 35 compounds), polychlorinated dioxins and furans (PCDF/PCDD, 18 compounds), chlorinated pesticides (19 compounds) and polychlorinated biphenyls (PCB, 6 compounds). For these compounds a group-wise hazard assessment may be appropriate selecting 2-3 "representative" compounds or "worst case" compounds from each group. This approach will significantly reduce the number of compounds for which further evaluation needs to be done (from 121 to below 50). For the "black" compounds in the water phase a similar reduction cannot be achieved, as the 56 compounds are more evenly distributed between the 12 groups shown in Fig. 6. Taking the overlapping 33 compounds into account, the total number of stormwater priority pollutants for both water and solid phases is about 75 compounds, and though this may be considered a high number of compounds to do hazard assessments for, it is still a significant reduction, compared to the initial 233 potential stormwater priority pollutants.

\subsection{Comparison to other classification schemes}

The 233 stormwater related compounds that were categorized according to the RICH procedure was also classified according to three European chemical ranking

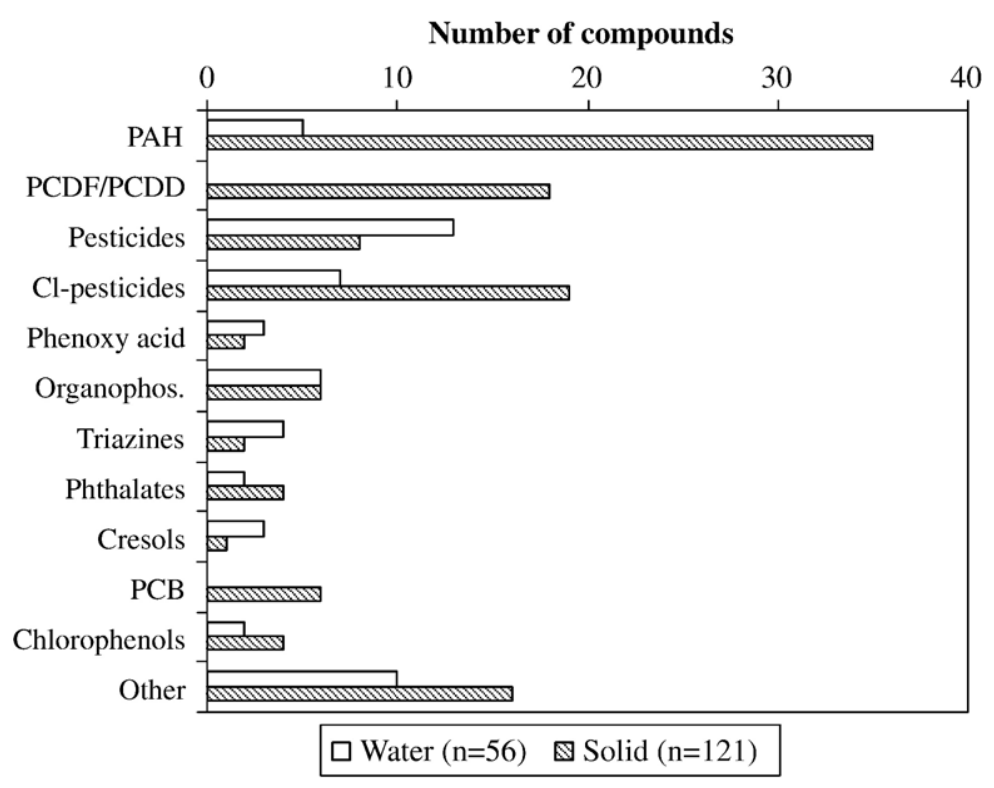

Fig. 6. Distribution of identified stormwater priority pollutants between groups of organic chemicals. PAH: polyaromatic hydrocarbons; PCDF/ PCDD: polychlorinated dibenzofurans/dioxins; PCB: polychlorinated biphenyls. 
procedures: The Persistence-Bioaccumulation-Toxicity (PBT) criteria (EU Commission, 2003), the "very persistent, very bioaccumulative" (vPvB) criteria (European Commission, 2003), and the EU environmental hazards classification system (European Commission, 1999) The outcome of this classification is shown in Table 2 along with the criteria of each classification scheme. It was found that, 31 of the 233 compounds could not be classified by any of the traditional classification schemes due to lack of data. The lack of data is especially pronounced for toxicity studies and therefore a total of 74 of the 233 compounds could not be classified in the PBT or $\mathrm{N}$-classification schemes.

It was found that 31 of the compounds classified as vPvB were also classified as PBT and N50/53. However, by comparing the compounds classified as either PBT, vPvB, N-R50, or N-R50/53 a list of a list of 153 compounds is established. Applying the RICH procedure to the 233 compounds allowed for decision to be made for 206 of these and the lack of toxicity data did thereby not hamper the evaluation seriously. This is attributed to the tiered approach applied in the RICH procedure, where basic physico-chemical parameters are used in the first filter allowing for selection even when data on toxicity is lacking. Compared to other classification schemes, the outcome of the RICH procedure focuses on the phases relevant for monitoring or risk assessment, thereby refining the list of "compounds of concern" to 56 for water phase and 121 for solid phase (Table 2, Fig. 5) contaminants as compared to the 153 compounds resulting from existing classification schemes.

\subsection{Applicability of methodology}

For selection of priority substances in relation to the Water Framework Directive (European Commission, 2000) the so-called COMMPS procedure (Combined
Monitoring-based and Modelling-based Priority Setting) has been applied (Denzer et al., 1999). This procedure is based on a scoring system for ranking of chemicals in relation to relevance, exposure, and effects. Whereas selection criteria in COMMPS is based on exposure and effects assessments, the RICH procedure is designed for hazard identification and ranking of chemicals and thereby focusing on the chemicals for which estimations of predicted environmental concentrations (PEC) and predicted no-effect concentrations (PNEC) are relevant. Thus, the RICH procedure can be used as a stand-alone tool for selection of potential priority pollutants or it can be integrated in larger priority setting frameworks like COMMPS or the CHIAT-procedure (Eriksson et al., 2005).

As is case for all procedures for prioritization of chemicals of concern, the lack of data and/or data availability represented a major limitation of using the RICH procedure. This shortage of data was illustrated by the fact that 25 of the potential stormwater priority pollutants could not be evaluated due to lack of basic physicochemical data and/or data on bioaccumulation, persistence, and ecotoxicity (Fig. 5). For these chemicals additional data searching, testing, and/or estimation using e.g. QSAR is required. In the application of the RICH-procedure it was found that the major advantages are: 1) it can be used generally for identifying selected priority pollutants for evaluation of different strategies for handling of storm- and wastewater, 2) it can be used for selection of priority pollutants to be included in monitoring programmes, 3) it represents a general framework for selecting pollutants which is transparent and adaptive to the specific scenario in focus. The methodology presented here is focused on compounds being discharged with urban stormwater to surface water, but the concept of "funnels and filters" may be applicable to other environmental compartments (e.g. soil and groundwater) after

Table 2

Classification of stormwater relevant compounds $(n=233)$ in chemical ranking procedures and criteria for these procedures according to European Commission $(1999,2003)$

\begin{tabular}{|c|c|c|c|c|c|c|c|}
\hline \multirow[t]{2}{*}{ Classification } & \multicolumn{2}{|c|}{ Stormwater compounds } & \multicolumn{5}{|l|}{ Classification criteria } \\
\hline & Classified & Lack of data & Toxicity (EC50) & & Degradability (freshwater) & & Bioaccum. $\left(\log K_{\mathrm{ow}}\right)$ \\
\hline PBT & 41 & 74 & $<0.1^{\mathrm{a}} \mathrm{mg} / \mathrm{l}$ or $\mathrm{CMR} / \mathrm{E}$ & AND & $T_{1 / 2}>40 \mathrm{~d}$ & AND & $>4.3^{\mathrm{b}}$ \\
\hline vPvB & 85 & 31 & & & $T_{1 / 2}>60 \mathrm{~d}$ & AND & $>4.7^{\mathrm{b}}$ \\
\hline $\mathrm{N}, \mathrm{R} 50$ & 17 & 74 & $<1 \mathrm{mg} / \mathrm{l}$ & AND & Ready & AND & $<3$ \\
\hline N, R50/53 & 88 & 74 & $<1 \mathrm{mg} / \mathrm{l}$ & AND & Not ready & OR & $>3$ \\
\hline "Black" water phase & 56 & 25 & $\mathrm{RICH}$ procedure & & & & \\
\hline "Black"solid phase & 121 & 25 & $\mathrm{RICH}$ procedure & & & & \\
\hline
\end{tabular}

\footnotetext{
${ }^{\mathrm{a}}$ The criteria of long-term NOEC $<0.01 \mathrm{mg} / \mathrm{l}$ was translated to (EC50 or LC50) $<0.1 \mathrm{mg} / \mathrm{l}$ for base set organisms. ${ }^{\mathrm{b}}$ The original BCF-criteria was transformed into $\log K_{\mathrm{ow}}$ criteria assuming a $10 \%$ lipid content in aquatic organisms $\left(\mathrm{BCF}=(\right.$ lipid content $\left.) \cdot K_{\mathrm{ow}}\right)$. PBT: persistent, bioaccumulative, and toxic. vPvB: very persistent and very bioaccumulative. N: environmentally hazardous; R50: very toxic to aquatic organisms. R53: may cause long-term effects on aquatic organisms. CMR/E: carcinogenic, mutagenic, reproductive damaging, or endocrine disrupting.
} 
"construction" of appropriate filters or for other types of wastewater (grey, household and industrial wastewater, urine, faeces, organic waste from households). Moreover, only screening procedures for organic chemicals are included in the present paper, but "funnels" for e.g. heavy metals or nutrients may also be constructed and fitted with filters appropriate for the screening of problems and hazards related to these specific compound groups.

\section{Additional information}

All 233 stormwater compounds and their individual profile obtained using the RICH-procedure can be viewed at http://chiat.er.dtu.dk/hazard_index.php.

\section{Acknowledgements}

This study was financed by the Technical University of Denmark, EU-funded DayWater "Adaptive Decision Support System for Stormwater Pollution Control", contract no EVK1-CT-2002-00111, the Urban Water program and VA-Forsk, Sweden. Lykke Christel Oldenburg and Thomas Aabling are thanked for their assistance in retrieving data for the stormwater pollutants. Christian Grøn, DHI Water and Environment is thanked for his valuable comment on a previous version of the manuscript.

\section{References}

Bickford G, Toll J, Hansen J, Baker E, Keessen R. Aquatic ecological and human health risk assessment of chemicals in wet weather discharges in the Sydney Region, New South Wales, Australia. Mar Pollut Bull 1999;39:335-45.

Boethling RS, Lynch DG, Jaworska JS, Tunkel JT, Thom GC, Webb S. Using Biowin, Bayes, and Batteries to predict ready biodegradability. Environ Toxicol Chem 2004;23:911-20.

Christensen FM, Andersen O, Duijrn NJ, Harremoës P. Risk terminology - a platform for common understanding and better communication. J Hazard Mater A 2003;103:181-203.

Eriksson E, Baun A, Mikkelsen PS, Ledin A. Chemical hazard identification and assessment tool for evaluation of stormwater priority pollutants. Water Sci Technol 2005;51:47-55.
European Commission. Directive 1999/45/EC of the European Parliament and of the Council of 31 May 1999 concerning the approximation of the laws, regulations and administrative provisions of the Member States relating to the classification, packaging and labelling of dangerous preparations. Official Journal of the European Communities, vol. L 200.; 1999. p. 1-68.

European Commission. Directive 2000/60/EC of the European Parliament and of the Council of 23 October 2000 establishing a framework for Community action in the field of water policy. Official Journal of the European Communities, vol. L327.; 2000. p. 1-72.

European Commission. Technical guidance document on risk assessment. Part II. Brussels: European Commission; 2003.

Denzer S, Herrchen M, Lepper P, Müller M, Sehrt R, Storm A, et al. Revised proposal for a list of priority substances in the context of the Water Framework Directive (COMMPS Procedure). 98/788/3040/ DEB/E1. Schmallenberg, Germany: Fraunhofer-Institut; 1999.

Hansen BG, Van Haelst AG, Van Leeuwen K, Van der Zandt P. Priority setting for existing chemicals: European Union risk ranking method. Environ Toxicol Chem 1999;18:772-9.

Ledin A, Eriksson E, Baun A, Aabling T, Mikkelsen PS. CHIAT Chemical Hazard Identification and Assessment Tool. En metodik för utvärding av kemiske risker i samband med hantering av dag-och avloppsvatten.(A methodolgy for chemical risk assessment i relation to use and discharge of stormwater and wastewater) VA Forsk Rapport 2005-09. VA Forsk Svensk Vatten, Stockholm, Sweden (in Swedish), 2005.

Makepeace DK, Smith DW, Stanley SJ. Urban stormwater quality: summary of contamination data. Crit Rev Environ Sci Technol 1995;25:93-139.

Müller-Herold U, Morosini M, Schucht O. Choosing chemicals for precautionary regulation: a filter series approach. Environ Sci Technol 2005;39:683-91.

Snyder EM, Snyder SA, Giesy JP, Blonde SA, Hurlburt GK, Summer CL, et al. SCRAM: A scoring and ranking system for persistent, bioaccumulative and toxic substances for the North American Great Lakes. Part I. Structure of the scoring and ranking system. Environ Sci Pollut Res 2000;7:51-61.

Swanson MB, Socha AC, editors. Chemical ranking and scoring: guidelines for relative assessments of chemicals. Pensacola, FL: SETAC Press; 1997.

Swanson MB, Davis GA, Kincaid LE, Schultz TW, Bartmess JE. A screening method for ranking and scoring chemicals by potential human health and environmental impacts. Environ Toxicol Chem 1997; 16:372-83. 